\title{
LAND SUBSIDENCE OBSERVED IN THE MERCHTEM AREA (FLANDERS) - 30 YEARS OF SAR DATA ASSOCIATED TO GROUNDWATER WITHDRAWAL?
}

\author{
Atefe Choopani ${ }^{1,2}$, Pierre-Yves Declercq ${ }^{1}$, Alain Dassargues ${ }^{2}$, Xavier Devleeschouwer $^{1}$ \\ ${ }^{1}$ Royal Belgium Institute of Natural Sciences, Geological Survey of Belgium, Rue Jenner 13, 1000 \\ Brussels, ${ }^{2}$ Liège University, Hydrogeology \& Environmental Geology, Urban \& Environmental \\ Engineering, allée de la Découverte 9, 4000 Liège
}

\begin{abstract}
A land subsidence affecting several towns at the joining limits of the Belgian Provinces of East Flanders, Antwerp and Flemish Brabant is followed during the last three decades. ERS 1-2, ENVISAT, TerraSAR-X and Sentinel 1A satellites SAR scenes were processed from 1992 till October 2020 to map the land subsidence evolution. The subsidence corresponds to a surface area of $220 \mathrm{~km}^{2}$ during the ERS1/2 time interval distributed over three distinct subsidence bowls. During the ENVISAT and TerraSAR-X time interval, only one residual subsidence bowl was mapped affecting a surface area of about $70 \mathrm{~km}^{2}$. Several towns (Londerzeel and Steenhuffel) remained in the center of the subsidence bowl. The annual average negative velocity values range between -5.99 and $-0.5 \mathrm{~mm} /$ year. More recently, during the Sentinel 1A period, the subsidence bowl has lost half of its surface reaching $36 \mathrm{~km}^{2}$. The velocity values have also decreased during the period 2016-2020.
\end{abstract}

Index Terms - Land subsidence, PSInSAR, long-term ground movements, aquifer withdrawal

\section{INTRODUCTION}

Nowadays, land subsidence is of major concern as geological risk-hazard management for the stakeholders and administrative authorities. Land subsidence rate related to groundwater exploitations are quite important in major cities like Mexico (from $-7 \mathrm{~cm} /$ year with Sentinel 1A [1] to -35 $\mathrm{cm} /$ year during ERS [2]. Similar negative rates inducing gradual land subsidence are also observed in other major megacities linked to severe groundwater exploitations. In this research, the spaceborne MT-InSAR technique (i.e., PSInSAR technique) is used to map the ground displacements in an area located at about $25 \mathrm{~km} \mathrm{NW}$ of the Brussels Region. The region of interest (ROI) covers a large area containing the towns of Merchtem, Aalst, Opwijk and Steenhuffel. This research has two main goals: i) to map the land subsidence bowl (already described in [3]) during three decades by adding SentinellA data, ii) to process TerraSAR-X Stripmap SAR images to map precisely the most recent evolution of the subsidence bowl.

\section{GEOLOGICAL AND GEOGRAPHICAL SETTING}

The ROI is located to the NW of Brussels and is present across the limits of three Belgian Provinces (East Flanders to the West, Antwerp to the north and the Flemish Brabant to the south). Several rivers (the Dender, the Scheldt and the Groote Molenbeek) are cross cutting the ROI. The alluvial plains are formed by unconsolidated Holocene sediments. The relief at higher altitude is associated to a plateau of Pleistocene rocks. The subcrop of the ROI corresponds to almost tabular Tertiary and Mesozoic rocks gently dipping to the North. The basement of the ROI is made of folded and faulted Paleozoic (from Cambrian to Silurian) rocks belonging to the Caledonian Brabant Massif. Due to several periods of weathering, the top of the basement is highly fractured and altered into clay deposits. The entire Tertiary and Secondary sedimentary succession contain 6 aquifer horizons. Most of the groundwater pumping sites are drilled in the Ledo-Paniselian sandy aquifer (i.e., Eocene in age) and the aquifers below. The Cretaceous aquifer is separated by an aquitard horizon from the Ledo-Paniselian aquifer. Finally, at the bottom of the sequence, directly below the Cretaceous aquifer, the weathered and fractured zone of the Paleozoic bedrock is also an important and deep aquifer.

\section{DATA AND METHODOLOGY}

For this research, only the PSInSAR technique is used to analyze the ground movements identified by using different satellite SAR data. During the processing chain, the different contributing phases of each Persistent Scatterer (PS) are removed, leaving only the contribution related to the displacement. The oldest processed SAR images are those from the C-band ERS and ENVISAT satellites covering, respectively, the time interval from 1991 to 2001 and from 2003 to 2010. 67 SAR images from ERS1/2 (Track 423, descending geometry with the Master image corresponding to the 18 July 1998). 73 SAR images from ENVISAT (Track 423, descending geometry with the Master image corresponding to the 15 August 2007) are processed. X-band TerraSAR-X satellite SAR images are also processed to produce high-resolution spatial PS density covering the ROI. 


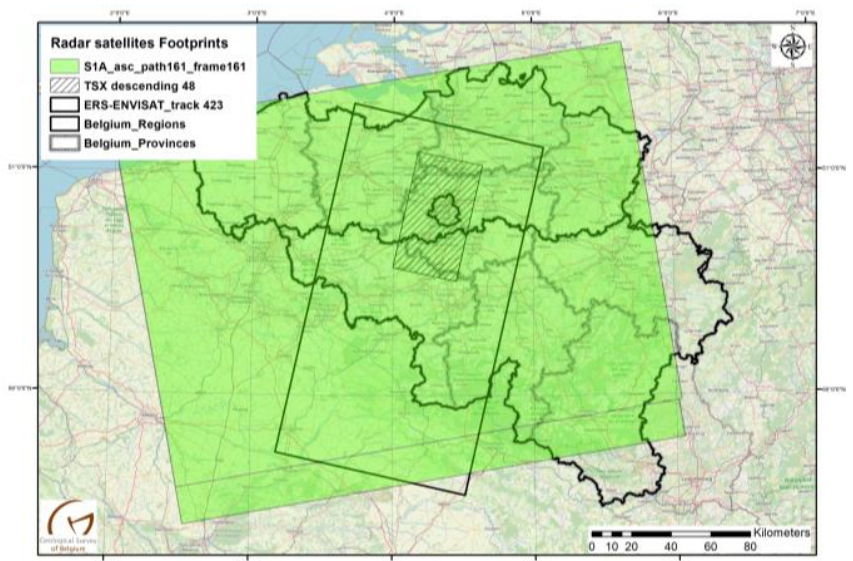

Figure 1: footprints of the different SAR satellite used in this research (i.e. ERS1/2, ENVISAT, TerraSAR-X, Sentinel 1A) covering the ROI area (small rectangle on the NW of the Brussels Region). The limits of the different administrative provinces (grey) and of the Belgium regions (black) are reported.
Finally, the C-band Sentinel 1A satellite are also processed using the ascending geometry (Path 88, Frame 163, Swath 2) covering the time interval (2016-2020). During the processing of the SAR images, precise orbits from the Delft Institute of Earth Observation and Space Systems were used to minimize orbital errors and a master scene was selected for each set of SAR images to minimize the temporal and spatial baselines [4].

\section{LAND SUBSIDENCE EVOLUTION}

The ongoing research on the ROI is provided under the framework of the BELSPO Brain funded LASUGEO project (monitoring LAnd SUbsidence caused by Groundwater exploitation through gEOdetic measurements). This study is built on existing data already published for ERS1/2, ENVISAT and TerraSAR-X [2]. During the ERS1/2 time interval (1992-2001), the PS data have shown the presence of three subsidence bowls distributed over different towns in the ROI (Figure 2). The western bowl (73

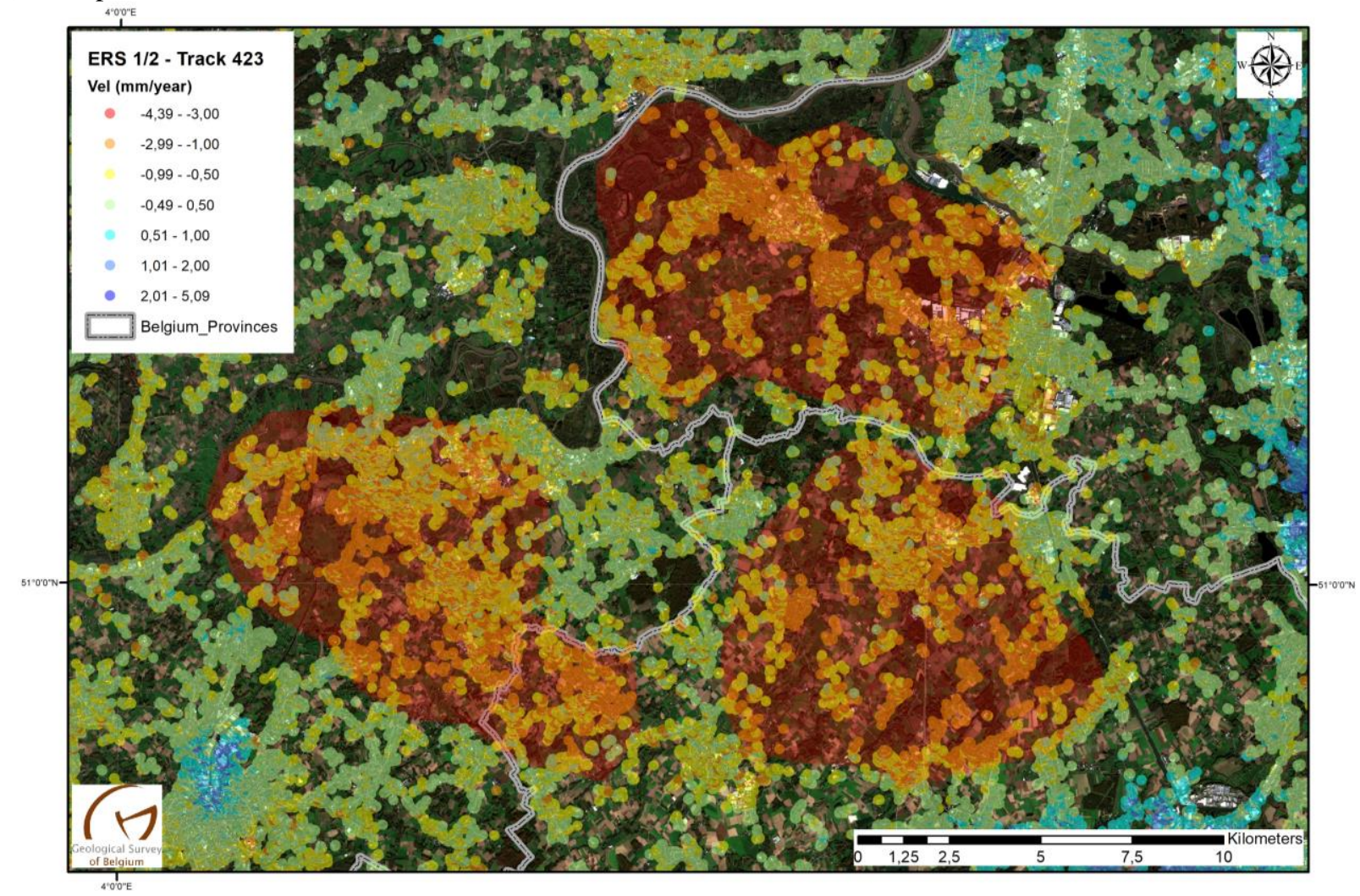

Figure 2: PSInSAR velocity map showing ground subsidence (in orange/red colours with velocities ranging between -1.0 to $-4.39 \mathrm{~mm} /$ year). The ROI is in Flanders across three different Belgian Provinces (East Flanders to the west, Antwerp to the North and the Flemish Brabant to the south). The three different subsidence bowls (in transparent red) across the ROI area. $\mathrm{km}^{2}$ ) is covering the towns of Dendermonde, Lebbeke and Opwijk. The northern bowl $\left(77 \mathrm{~km}^{2}\right)$ is centered on the Puurs Sint-Amands town, and the southern bowl $\left(70 \mathrm{~km}^{2}\right)$ is covering the town of Londerzeel. The cumulated surface of these different bowls reaches a total of $220 \mathrm{~km}^{2}$. The low amplitude ground subsidence deformations are relatively well defined and surrounded by opposite ground deformations revealing uplifting conditions. The three bowls 
are centered on the most negative annual velocities identified across the ROI.
The third period corresponds to the TerraSAR-X data (2011-2014) covering only a part of the ROI and during a

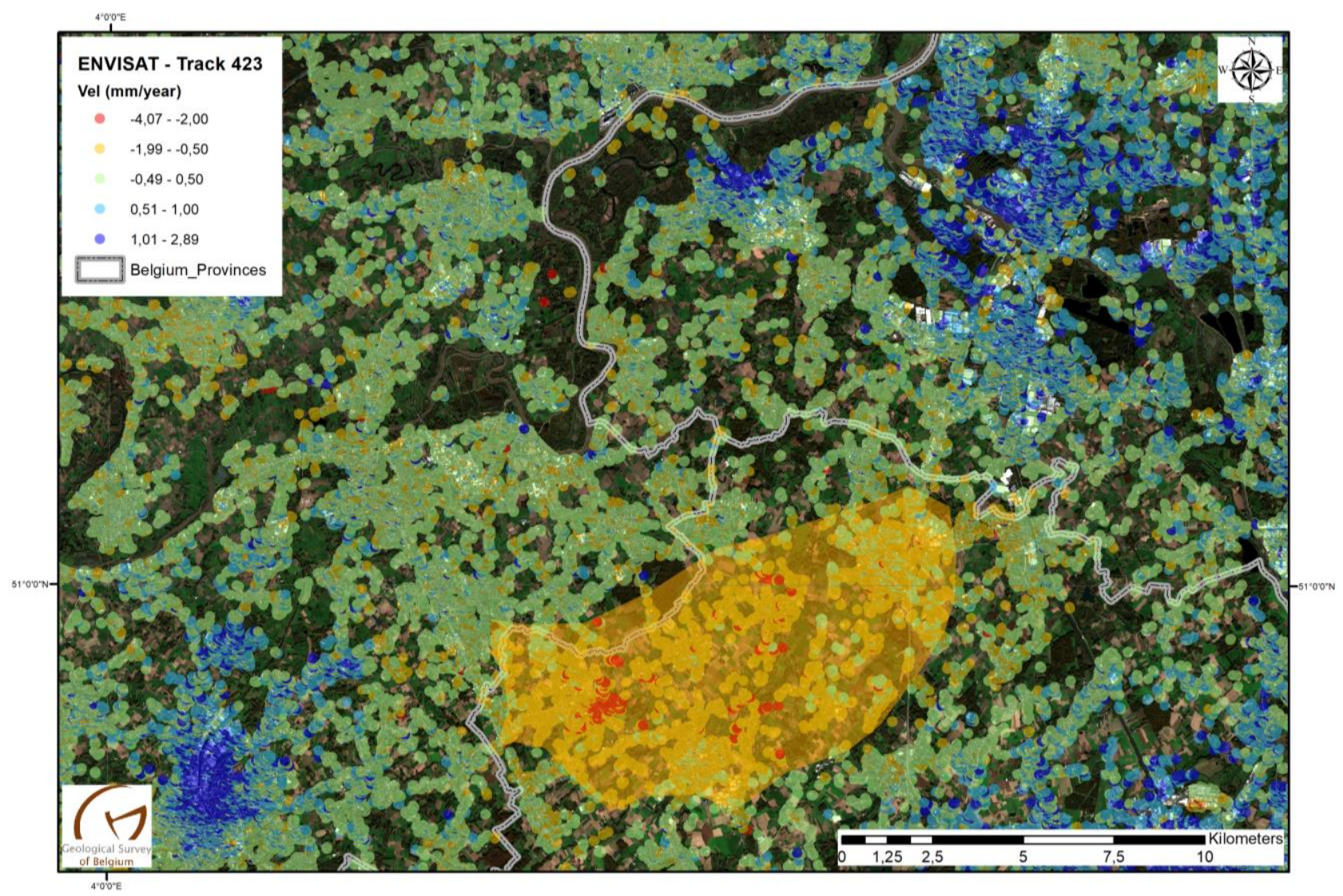

Figure 3: PSInSAR velocity map showing ground subsidence (in yellow to red colours with velocities ranging between -0.5 to $-2.47 \mathrm{~mm} /$ year). The ROI is in Flanders across three different Belgian Provinces (East Flanders to the west, Antwerp to the North and the Flemish Brabant to the south). The remaining subsidence bowl (in transparent orange) across the ROI area.

The second period is associated to the ENVISAT SAR scenes (2003-2010) covering the whole ROI area. During this interval of time, only one main bowl $\left(70 \mathrm{~km}^{2}\right)$ is present in the SW part of the ROI. This subsidence bowl corresponds to the merge of the two southern bowls identified on the figure 2. The western bowl is strongly reduced towards the south where only half of the surface still present negative velocity values. A major change of the ground deformations is thus affecting the towns of Dendermonde, Lebbeke and Opwijk, which are associated with positive annual average velocity values (Figure 3 ). The subsidence bowl is still covering an area of $70 \mathrm{~km}^{2}$. The annual average velocity values $(-0.5$ to $-2.47 \mathrm{~mm} /$ year $)$ characterizing the subsidence bowl are also lower compared to the ERS1/2 data. The towns of Merchtem, Opwijk and Londerzeel are still included in the remaining subsidence bowl. very short period (Figure 4). These data will be hopefully updated with SAR scenes covering a longer time interval. These data indicate that the surface area $\left(69 \mathrm{~km}^{2}\right)$ of the subsidence bowl is almost similar to the previous period. On the contrary, the ground deformation amplitude is marked by an increase of the annual average velocity values $(-0.5$ to $-5.99 \mathrm{~mm} /$ year). It is obvious that the velocity values are distributed along a concentric pattern where the ground deformations are centered on the towns of Steenhuffel and Londerzeel.

Finally, the use of the Sentinel 1A SAR scenes allowed to map the most recent spatial and temporal evolution (2016-2020) of this land subsidence bowl (Figure 5). As determined after the SAR processing, the subsidence bowl is still visible and centered on the Steenhuffel town. The surface area has been again reduced to $36 \mathrm{~km}^{2}$ but remains active in terms of the amplitude of the annual average velocity values.

\section{ONGOING WORK}

The last three decades have shown a major change of the ground deformations affecting the ROI from a large area affected by land subsidence towards a reduced but still active subsidence zone. 


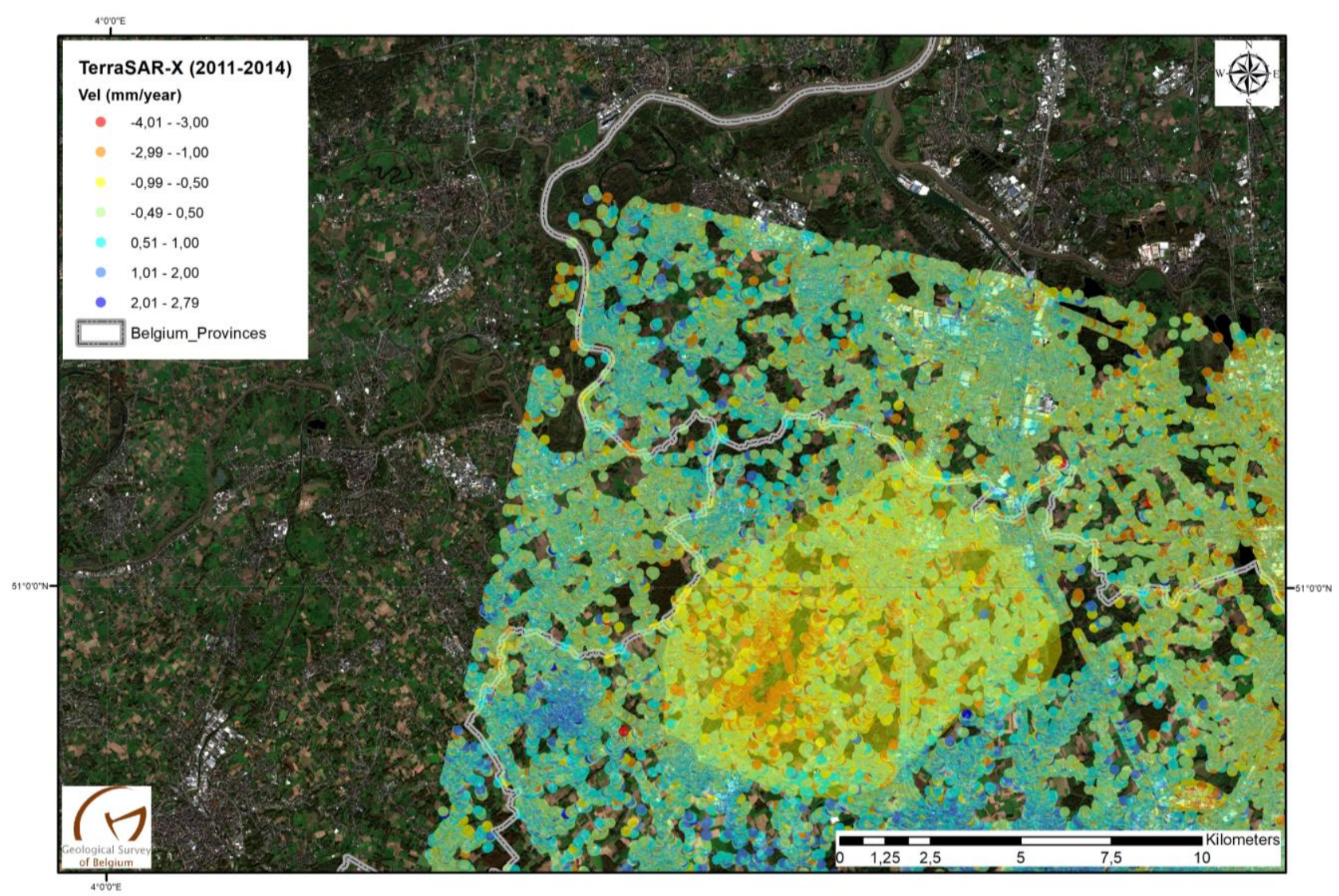

Figure 4: PSInSAR velocity map showing ground subsidence (in yellow to red colours with velocities ranging between -0.5 to $-5.99 \mathrm{~mm} /$ year). The ROI is in Flanders across three different Belgian Provinces (East Flanders to the west, Antwerp to the North and the Flemish Brabant to the south). The remaining subsidence bowl (in transparent yellow) across the ROI area.

The surface area has decreased from $220 \mathrm{~km}^{2}$ to 36 $\mathrm{km}^{2}$. The processing of recent TerraSAR-X Stripmap images would bring an updated view at high-resolution of the ROI. The ongoing work will explain the causes of this land subsidence linked to the groundwater (over)exploitation of an aquifer in the area where industrial activities have been noticed (i.e., breweries, [4]). Three decades of land subsidence mapping suggest an ongoing active process of groundwater recharge leading to a major rebound of the ground deformations inducing uplifting conditions.

The ongoing work intend to extensively add new TerraSAR-X images to update the data allowing to have a very high-resolution analysis of the recent ground deformations. The possible groundwater overexploitation needs to be established through a transient hydrogeological model considering all the stress-factors applied to the aquifers. The measured cumulated compaction estimation due to the subsidence around the Steenhuffel town will be compared with 1D geomechanical model results. The latter will be performed using geotechnical effective stresses as deduced from the pore pressure distribution from the hydrogeological model [5-9]. These different steps will be done by the partners of the LASUGEO project that are involved in the different case study areas.

\section{CONCLUSIONS}

The monitoring of land subsidence phenomenon affecting a large area $\left(220 \mathrm{~km}^{2}\right)$ is extremely important for estimating their impact on the stability of the anthropic structures, on civil engineering infrastructures present in the area. The comparison of different geodetic techniques (GNSS stations, gravimetry) will also validate the outcomes of the SAR imagery processing chain applied in this project.

\section{ACKNOWLEDGEMENTS}

This research is funded under the Brain BELSPO program called LASUGEO (2019-2023) entitled "monitoring LAnd SUbsidence caused by Groundwater exploitation through gEOdetic measurements". The last author is the coordinator of the LASUGEO Brain project. The first author has started a $\mathrm{PhD}$ thesis on the LASUGEO Brain project at the University of Liège in November 2020. We would like to thank our colleague, Dr Jan Walstra, for the processing on the ERS SAR images made during the Brain GEPATAR project. 


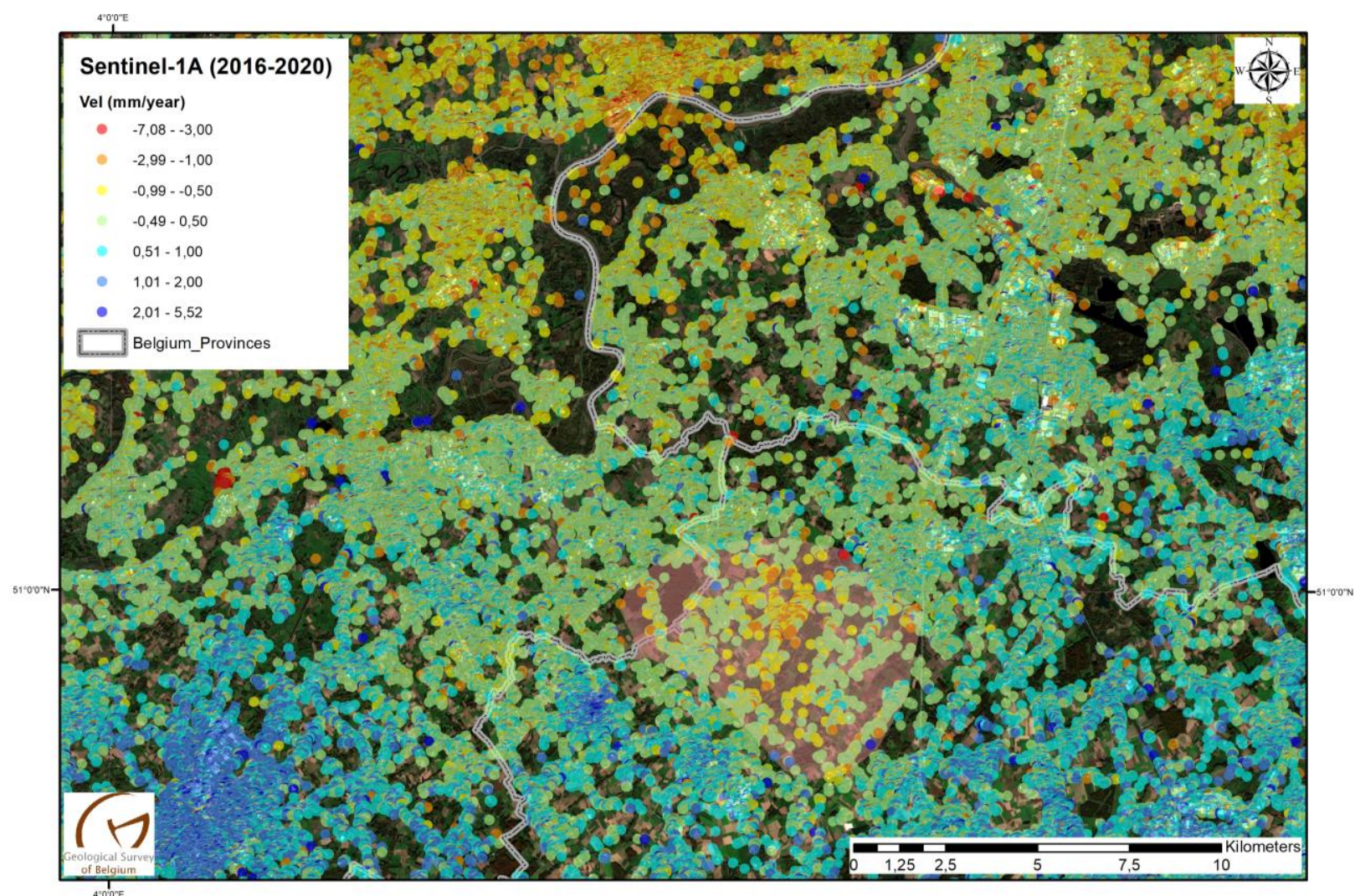

Figure 5: PSInSAR velocity map showing ground subsidence (in yellow to red colours with velocities ranging between -0.5 to $-3.8 \mathrm{~mm} / \mathrm{year})$. The ROI is in Flanders across three different Belgian Provinces (East Flanders to the west, Antwerp to the North and the Flemish Brabant to the south). The remaining subsidence bowl (in transparent red) across the ROI area.

\section{REFERENCES}

[1] F. Cigna, B. Osmanoğlu, E. Cabral-Cano, T.H. Dixon, J.A. Ávila-Olivera, V.H. Garduño-Monroy, C. DeMets, S. Wdowinski, Monitoring land subsidence and its induced geological hazard with Synthetic Aperture Radar Interferometry: A case study in Morelia, Mexico, Remote Sensing of Environment, 117, pp. 146-161, 2012. [2] T. Strozzi, U. Wegmuller, C.L. Werner, A. Wiesmann, V. Spreckels, JERS SAR interferometry for land subsidence monitoring. IEEE Transactions on Geoscience and Remote Sensing, 41/7, pp. 1702-1708, 2003.

[3] P.-Y. Declercq, J. Walstra, P. Gérard, E. Pirard, D. Perissin X. Devleeschouwer, Subsidence related to groundwater pumping for breweries in Merchtem are (Belgium) highlighted by Persistent Scaterrer Interferometry, International Journal of Applied Earth Observations and Geoinformation, Elsevier, 63, pp. 178-185,
2017.

[4] B. Kampes and S. Usai, Doris: The Delft Object-Oriented Radar Interferometric Software; Citeseer, 16, p. 20, 1999.

[5] A. Dassargues, C. Schroeder, and X.L. Li, Applying the Lagamine model to compute land subsidence in Shanghai.

Bulletin of Engineering Geology and the Environment, 47, 13-26, 1993.

[6] A. Dassargues, J.P. Radu, R. Charlier, X.L. Li and Q.F. Li, Computed subsidence of the central area of Shanghai, Bulletin of Engineering Geology (IAEG) 47, pp.27-50, 1993.

[7] A. Dassargues and J. Zhang, Land subsidence in Shanghai: hydrogeological conditions and subsidence measurements, Bulletin of Engineering Geology (IAEG) 46, pp. 27-36, 1992.

[8] A. Dassargues, Hydrogeology: groundwater science and engineering, chapter 6 , Taylor \& Francis CRC press, Boca Raton. 2018.

[9] A. Dassargues, Hydrogéologie appliquée : science et ingénierie des eaux souterraines (in French), chapitre 6, Dunod. Paris. 2020 